\title{
Cenas do cotidiano na educação infantil: desafios da integração entre cuidado e educação
}

\author{
Maria Aparecida Guedes Monção'
}

\section{Resumo}

0 objetivo deste artigo é discutir a rotina das crianças na educação infantil, especificamente daquelas de zero a quatro anos de idade, tendo como foco os momentos de descanso e alimentação. Nessa etapa do atendimento educacional, as relações dialógicas entre os adultos e as crianças e a integração entre cuidado e educação são pressupostos essenciais de uma educação infantil de qualidade, condição para garantia dos direitos fundamentais dos bebês e das crianças pequenas. A investigação consistiu em uma pesquisa qualitativa, mediante estudo de caso de cunho etnográfico, realizado em 2010 e 2011, em um Centro de Educação Infantil (CEI) público da rede municipal de São Paulo, que atende crianças de zero a quatro anos. Os procedimentos metodológicos conjugaram observação participante, análise documental e entrevista semiestruturada com a equipe do CEI e com as famílias. A investigação envolveu revisão da literatura, tendo como principais referências Barbosa, Batista, Coutinho, Guimarães, Korczak, Tristão e Wallon. Os resultados evidenciaram que as emoções expressas pelas crianças nos momentos das refeições e descanso são, em grande medida, desconsideradas. Constatou-se também contradições entre as proposições de integração entre cuidado e educação expressas no projeto pedagógico e os discursos e práticas das professoras efetivadas junto às crianças. 0 estudo concluiu que é fundamental inserir as temáticas de cuidado com o corpo - alimentação, higiene, descanso, saúde - como parte da formação continuada e dos planejamentos semanais realizados nas instituições de educação infantil.

\section{Palavras-chave}

Educação infantil - Rotina na educação infantil - Relação educadores-crianças - Integração entre cuidado e educação.

I- Universidade Cidade de São Paulo, São 


\title{
Scenes of everyday life in early childhood education: challenges facing the integration of care and education
}

\author{
Maria Aparecida Guedes Monção'
}

\begin{abstract}
The purpose of this article is to discuss the routine of children in early childhood education, especially of those aged zero to four years, focusing on the moments of rest and feeding. At this stage of educational service, the dialogical relationships between adults and children and the integration between care and education are fundamental assumptions for a quality early childhood education, a condition to ensure the fundamental rights of babies and very young children. This qualitative investigation consisted of a case study of ethnographic nature, conducted in 2010 and 2011, in a Centro de Educação Infantil (CEI - Early Childhood Education Center) of the public school system of São Paulo city, Brazil, which serves children aged from 0 to 4 years. The methodological procedures included participant observation, documentary analysis and semistructured interviews with the CEI team and children's families. The investigation involved literature review, and the main references were Barbosa, Batista, Coutinho, Guimarães, Korczak, Tristão, and Wallon. The results evidenced that the emotions expressed by children at the times of meals and rest are, to a great extent, disregarded. I have also found contradictions between the propositions of integrating care and education included in the pedagogical project and teachers' discourses and practices with the children. The study concluded that it is essential to include the topics of care of the body - food, hygiene, rest, and health - as part of continuing teacher education and the weekly planning conducted in institutions of early childhood education.
\end{abstract}

\section{Keywords}

Early childhood education - Routine in early childhood education - Teacher-children relationship - Integration between care and education.

I- Universidade Cidade de São Paulo, São

Paulo, SP, Brasil.

Contact: maguedes@maxpoint.com.br 


\section{Introdução}

A educação infantil é a primeira etapa da educação básica, cuja finalidade é proporcionar o desenvolvimento integral das crianças pequenas, em ação compartilhada com suas famílias. Para nortear as reflexões empreendidas ao longo do texto, pautamo-nos na proposição de que as políticas públicas para a primeira infância, bem como as práticas pedagógicas desenvolvidas no interior das instituições, devem ter como base os direitos fundamentais das crianças pequenas e a escuta permanente de suas expressões e manifestações.

Considerar os direitos fundamentais das crianças como norteadores das políticas públicas e das práticas cotidianas apoia-se na compreensão da criança como sujeito de direitos, capaz de participar desde a mais tenra idade de seu processo de formação, e da infância como uma construção social e histórica, reconhecendo as instituições de educação infantil como contexto promotor da socialização das crianças pequenas em espaços coletivos, em parceria com suas famílias.

A predominância de pressupostos do senso comum sobre o cuidado e educação da criança pequena evidencia que, apesar dos avanços legais e das produções acadêmicas sobre a primeira infância, a criança, em muitas instituições, ainda é tida como objeto de tutela e não como sujeito de direitos. Isso se deve ao fato de, mesmo após a inserção das creches no sistema de educação, a visão sobre cuidado ainda se pautar na sua dimensão instrumental, ou seja, como forma de tomar conta, zelar, como ações sobre as ações das crianças, como se fosse possível educar sem cuidar ou cuidar sem educar.

Romper com o senso comum na educação infantil pressupõe pesquisa permanente de conhecimentos a respeito da criança, sua forma de sentir o mundo e as pessoas que a cercam; supõe um compromisso com a infância, buscando escutar as crianças de maneira profunda, rigorosa, de modo a distanciar-se de práticas que reforçam as relações de dominação entre adultos e crianças e não respeitam suas expressões, sentimentos, emoções.

É de fundamental importância resgatar a dimensão ética do cuidado e agir com sensibilidade para se reconhecer que a criança pequena precisa de afeto e atenção em seu processo de educação. Segundo Daniela Guimarães (2011, p. 48):

À medida que tiramos o cuidado de uma dimensão instrumental, de disciplinarização e controle sobre os corpos (na creche, isso significa, por exemplo, dar banho, alimentar, como exigências técnicas e rotineiras somente), para colocá-lo na esfera da existencialidade, ele contribui na concepção de educação como encontro da criança com o adulto, num sentido de diálogo, abertura e experiência compartilhada.

Ao considerarmos o cuidado em sua dimensão ética, aproximamo-nos da concepção de educação em sua integralidade, em que o cuidado é compreendido como algo indissociável do processo educativo.

0 objetivo deste artigo é discutir a rotina das crianças na educação infantil, com foco nos momentos de descanso e alimentação. Parte-se da concepção de que as relações dialógicas entre os adultos e as crianças e a integração entre cuidado e educação são pressupostos essenciais de uma educação infantil de qualidade, que respeita os direitos fundamentais dos bebês e das crianças pequenas.

0 presente texto é resultado de uma pesquisa qualitativa, ${ }^{1}$ realizada por meio de estudo de caso de cunho etnográfico. A pesquisa empírica ocorreu em um centro de educação

1- Trata-se de parte de um capítulo da tese Gestão democrática na educação infantil: o compartilhamento da educação da criança pequena, defendida no Programa de Pós-Graduação em Educação da Universidade de São Paulo, em 2013, sob a orientação do Professor Dr. Vitor Henrique Paro. 
infantil (CEI) ${ }^{2}$ da rede municipal de São Paulo, instituição pública que atende crianças de zero a quatro anos, no período de 2010 e 2011. Os procedimentos técnicos para a efetivação do estudo empírico conjugaram a observação participante, a análise documental e a entrevista semiestruturada com onze professoras, um professor, três coordenadoras pedagógicas, uma diretora, dois agentes técnicos de educação, um agente escolar, uma auxiliar de limpeza, uma auxiliar de cozinha, uma supervisora de ensino e dezoito famílias.

\section{A rotina da criança no CEI}

Observar e analisar o cotidiano de um Centro de Educação Infantil (CEI) envolve compreender a forma como o tempo da criança e dos adultos é organizado, ou seja, requer conhecer como é a rotina das crianças e adultos em uma instituição que abriga coletivamente crianças pequenas e bebês. Maria Carmen Silveira Barbosa (2006, p. 35) considera a rotina como uma "categoria pedagógica que os responsáveis pela educação infantil estruturam para, a partir dela, desenvolver um trabalho cotidiano nas instituições de educação infantil”. A autora ressalta a importância de compreender a rotina como um dos aspectos que compõem a vida cotidiana, tendo em vista sua complexidade, bem como sua amplitude.

A organização da rotina em uma instituição de educação infantil revela muito sobre as concepções de currículo, criança, infância e educação infantil. Na medida em que não se prioriza o tempo da criança para suas aprendizagens, o tempo institucional é o que determina as ações, prevalecendo a perspectiva tradicional de organização do cotidiano da criança, com traços marcantes de homogeneidade e ritualização. Isso também

2- Os nomes do Centro de Educação Infantil, professoras, equipe de gestão, crianças e famílias são fictícios. 0 desenvolvimento da pesquisa de campo baseou-se nos princípios éticos definidos pelos Padrões éticos na pesquisa em educação: primeiro documento, elaborado pelo Comitê de Ética na Pesquisa da Faculdade de Educação da Universidade de São Paulo (FEUSP). foi constatado nas pesquisas de Maria Carmen Silveira Barbosa (2006), Rosa Batista (1998), Ângela Maria Scalabrin Coutinho (2002) e Fernanda Carolina Dias Tristão (2004).

As observações e os relatos das professoras ${ }^{3}$ nas entrevistas revelaram que a estruturação do tempo da criança se dava por meio de um esquema de prescrição dos horários, em que eram distribuídos o tempo e os espaços coletivos que cada turma poderia frequentar. Ao longo do período de 2010 e 2011, em que a pesquisa foi realizada, não foram constatadas reflexões que problematizassem a relação entre a organização do tempo e as necessidades e desejos das crianças; tampouco houve estudo sobre a temática da organização do tempo e das práticas cotidianas com as crianças. Somente em uma das reuniões de avaliação, presenciei uma reflexão das professoras com relação ao curto período que as crianças tinham para realizar as refeições e o quanto isso era prejudicial para seu desenvolvimento. Em geral, as discussões giravam em torno da estruturação dos horários, especialmente do parque, na busca de não haver colisão entre os horários de cada sala ou com os horários da Escola Municipal de Educação Infantil (EMEI), que atende crianças a partir de quatro anos e fica situada no mesmo complexo educacional.

Assim, a questão era sempre posta em relação à disponibilidade dos espaços, não sendo levada em conta a necessidade da criança em si. Tal fator é preocupante, na medida em que os bebês e a as crianças pequenas precisam de um tempo longo para suas aprendizagens, que ocorrem por meio da experimentação, da investigação, da brincadeira e da interação com os adultos e com as outras crianças.

Foi possível identificar a manutenção da matriz que predomina na educação infantil desde sua origem, em que a rotina diária baseia-se na organização dos horários e espaços, alternando períodos entre ações de cada sala e atividades coletivas envolvendo diferentes grupos de crianças. Basicamente, o registro da rotina resumia-se a uma grade em que eram previstos

3- Por se tratar de ampla maioria de profissionais do gênero feminino (no CEl pesquisado havia apenas um professor), fiz a opção de adotar, ao longo do trabalho, o termo professoras quando me referisse ao grupo pesquisado. 
os momentos para atividades pedagógicas ${ }^{4}$, descritas como: utilizar TV, vídeo, sala multiuso, biblioteca, parque, piscina e outros espaços externos, além de atividades relacionadas às diferentes linguagens; e os momentos para alimentação, tais como desjejum, suco, almoço, lanche e jantar.

As professoras reconheciam que a rotina era um dos principais obstáculos para estabelecer relações dialógicas com as crianças e respeitar sua subjetividade, mas afirmavam que o descumprimento dos horários previstos poderia atrapalhar o trabalho pedagógico e causar atrasos nas outras salas. Desse modo, muitas vezes, as brincadeiras das crianças eram abruptamente interrompidas em função do horário da alimentação ou porque outra turma iria utilizar o espaço.

A forma como a maioria das professoras se referia à rotina permitiu-me perceber como é difícil para elas questionar as ações cotidianas estabelecidas, talvez porque garantir o respeito às necessidades individuais das crianças em um contexto coletivo ainda seja um princípio que necessite ser mais bem compreendido. As professoras temem perder o controle sobre as crianças e, da forma como está estruturada, a rotina lhes dá segurança. Além disso, é possível dizer que as políticas públicas de educação infantil, no município de São Paulo, não favorecem a constituição de uma rotina centrada na criança. Isso porque ignoram a especificidade dos bebês e das crianças pequenas e não garantem formação, materiais e condições adequadas de trabalho para as professoras e demais profissionais do CEI.

Nesse cenário, apesar de a rotina da unidade pesquisada não garantir o reconhecimento dos direitos das crianças em sua plenitude, as famílias entrevistadas julgaram-na positivamente. A maioria delas conhecia a rotina das crianças por meio das

4- Apesar de considerar que a adoção da terminologia atividades pedagógicas revela a cisão entre as ações de cuidados e educação, optei por manter essa nomenclatura para reportar com fidelidade a forma como esse momento era registrado e identificado na rotina do CEl. informações transmitidas pelas professoras ou equipe de gestão em reuniões e pelo registro nas agendas das crianças, e descreveu-a como sendo composta por momentos de brincadeira, leitura de histórias infantis, pintura com guache, filmes, passeios, andar de motoca, desenhos, colagem, alimentação e sono.

Indagadas sobre se gostariam de saber mais sobre a rotina dos filhos, a maioria das famílias considerou isso desnecessário, pois confiava no preparo das professoras para lidar com as crianças e no apoio técnico da nutricionista para a composição do cardápio. Apenas duas mães mostraram o desejo de acompanhar um dia de rotina das crianças, para conhecê-la mais detalhadamente e ver como elas se comportavam.

Todas as famílias entrevistadas consideraram a rotina um ponto muito positivo do atendimento, por garantir às crianças a experiência de horários bem definidos para as atividades, diferentemente do contexto familiar, cujos horários não costumam ser tão rigorosos.

Os depoimentos das famílias revelaram que o CEI é referência para os pais no que se refere à educação dos filhos. Algumas mães assinalaram a dificuldade em colocar regras para os filhos, vendo a instituição educativa como um espaço que fazia isso e as orientava sobre como fazer. Citaram, como exemplo, a chupeta, que, no CEI, só podia ser usada pela criança na hora do descanso, mas cujo uso em casa era liberado; ou, ainda, o caso do sono durante o dia, uma vez que as crianças dormiam após o almoço no CEI e, em casa, as famílias não conseguiam levá-las a fazer o mesmo.

Essa diferença entre a postura das crianças no CEI e em casa mostrou-se um fator de reconhecimento das famílias com relação à competência das professoras para educar seus filhos corretamente. Os pais acreditavam que, muitas vezes, em casa "deseducavam" as crianças, por não terem rigor nos horários de alimentação e não conseguirem garantir a mesma autonomia dos filhos. Havia uma supervalorização do trabalho desenvolvido 
no CEI, sem considerar a diferença entre os contextos educacional e familiar. Essa visão parece fruto da falta de reflexão mais aguçada sobre a educação da criança em contextos coletivos. Reflete-se pouco sobre o compartilhamento da educação da criança, prevalecendo as matrizes vigentes desde as primeiras creches, com a desqualificação das famílias para educar, especialmente das pertencentes às camadas populares.

\section{Momentos de alimentação}

Ao longo do dia, as crianças faziam cinco refeições: café da manhã, suco, almoço, lanche da tarde e jantar. Esse momento da rotina era bem tumultuado, havia muito barulho. No início das observações, em 2010, a maioria das professoras permanecia junto às crianças nas mesas, acompanhando-as. Já em 2011, por diversas vezes, observei que as professoras conversavam entre si e, quando necessário, admoestavam de longe as crianças, dando pouca atenção a elas.

Os momentos do café da manhã e do lanche da tarde transcorriam da mesma maneira: as crianças conversavam muito umas com as outras, brincavam, às vezes, levantavam-se da cadeira, mas eram repreendidas para que permanecessem sentadas. Em muitos momentos, as crianças solicitavam a atenção da professora, mas a maioria delas nem percebia a manifestação da criança, pois estavam conversando entre si.

0 suco era servido após o café da manhã, no refeitório ou no ambiente em que as crianças estivessem realizando as atividades pedagógicas, ficando a cargo da professora decidir o local. Nesse momento, também foi possível verificar atitudes bastante severas com as crianças, como podemos ver nas notas do caderno de campo abaixo na sala do Berçário 2:

Todas as crianças se sentam no chão do solário e a professora Leonilda diz: "Quem não ficar quietinho não vai tomar suco!”
Leonilda em seguida adverte: "Não pode derramar, Felipe! Toma esse suco!”

A partir das 10h, era servido o almoço. 0 primeiro grupo a almoçar era o dos Berçários; na sequência, almoçavam as crianças das salas dos Minigrupos 1 e $2 .{ }^{5}$ No caso dos Minigrupos 2 , cada criança pegava seu almoço diretamente na cozinha. Tal como no momento do café, havia muito barulho e pouca interação entre as professoras e as crianças. Quando todas as crianças do grupo terminavam a refeição, a sobremesa e a água eram servidas, e, em seguida, todas se dirigiam ao banheiro para realizar a escovação dos dentes.

Por se tratar de crianças bem pequenas, as atividades de alimentação eram seguidas por atividades de higiene e sua realização ocupava um tempo significativo. Na maioria das vezes, as crianças ficavam sentadas, encostadas na parede do corredor, aguardando sua vez. As professoras repreendiam constantemente as crianças que se levantavam ou que brincavam nesse momento. Durante o período em que realizei as observações, apenas uma vez presenciei uma professora do Minigrupo 1 da tarde cantando junto às crianças, enquanto aguardavam.

As refeições dos bebês ocorriam de forma diferente das crianças maiores. Os bebês eram colocados em cadeirões no corredor ou na própria sala. As observações desse agrupamento em períodos distintos permitiram perceber professoras com muita atenção às crianças, mas muitas com abordagens severas, dando pouco acalanto quando os bebês choravam ao se alimentar.

0 horário para a realização dessa refeição era sempre rigoroso, dificultando o atendimento às necessidades individuais das crianças. Em março de 2010, por exemplo, um bebê do Berçário 1, ao retornar de um passeio, adormeceu. Não conseguiu acordar no horário e as professoras guardaram seu almoço. Entretanto,

5- Os grupos de crianças eram organizados em: Berçário 1, com crianças de quatro meses a um ano; Berçário 2, com crianças de um a dois anos; Minigrupo 1, com crianças de dois a três anos; Minigrupo 2, com crianças de três a quatro anos. 
segundo informações das professoras, não havia possibilidade de aquecê-lo.

Outro episódio no Berçário 1 ocorreu em abril de 2011 e foi relatado no livro de ocorrências pelas professoras da sala:

0 almoço do B1 atrasou nesta manhã e as professoras foram informadas pela coordenadora Marjorie que as cozinheiras disseram que estavam esperando a professora ir pedir, pois, se colocar nos pratinhos antes, pode cair algum bichinho. As professoras desconheciam esta função e também discordam, porque é o horário em que estão terminando as trocas, organizando os brinquedos utilizados, colocando babadores e levando os bebês para os cadeirões, de modo que às $10 \mathrm{~h} \mathrm{em}$ ponto a comida precisa estar nos pratos com temperatura adequada, pois já estão com muito sono e não aguentam esperar. Hoje o Sérgio ficou sem almoço porque dormiu antes de ser servido, acordou às $12 \mathrm{~h} 25 \mathrm{e}$ teve que comer bolacha doce. Estavam presentes nesta manhã as professoras Karin, Joana e Carolina (do período da tarde). Esta última acompanhou a turma até terminar o almoço. (Professoras Joana e Karin) ${ }^{6}$.

A análise desse relato levou-me a inferir que seu conteúdo expressa a insatisfação das professoras com a coordenadora pedagógica e com o atraso do almoço, e revela também que é tratado de forma natural e secundária o aspecto central dessa situação: o fato de a criança não ter almoçado, porque dormiu. Ao contrário da situação relatada anteriormente, em que as professoras tomaram o cuidado de guardar a alimentação para a criança - apesar de fria -, neste caso, não se percebeu nenhum questionamento ou preocupação com a criança. Oferecer bolacha no lugar de almoço para um bebê é algo inadmissivel e fere os direitos fundamentais da criança.

6- Transcrição do livro de ocorrências da unidade, abril de 2011.
Ao questionar a diretora sobre o fato, fui informada de que havia dois fatores que dificultavam a flexibilização dos horários das refeições das crianças: o primeiro diz respeito a uma norma da área de nutrição segundo a qual, após servir o almoço, as sobras devem ser descartadas, o que impossibilita guardar refeições para serem consumidas posteriormente; o segundo fator refere-se ao período de almoço da equipe de cozinha, que deve ser após o almoço das crianças, depois que a equipe organiza a cozinha.

A supervisora - que disse não ter ciência desse fato - informou que era o diretor quem coordenava esse processo junto aos funcionários, o que nos levou a supor que o olhar burocratizado das práticas cotidianas encobre as crianças, inclusive suas necessidades básicas. Questões como essa podem ser resolvidas por meio de uma conversa e uma acomodação interna que beneficie a criança, desde que os profissionais considerem isso um fator importante. Note-se que um fato sério de negligência com a criança foi registrado no livro de ocorrência interna e não houve nenhuma manifestação por escrito da equipe de gestão ou supervisora.

Situações como essas evidenciam como os conflitos entre os adultos professoras, equipe de cozinha e coordenadora pedagógica - afetam as crianças, provocando a negligência de seus direitos fundamentais. Para evitar a naturalização de situações como essa, ressaltamos a necessidade de inserir os momentos de alimentação como temáticas de planejamento e formação de extrema relevância, pois as ações desencadeadas junto às crianças nesses momentos comprometem seu desenvolvimento e promovem aprendizagens relativas às relações humanas. A articulação entre teoria e prática cotidiana e a reflexão sobre os direitos fundamentais da criança devem ser o norte desse processo reflexivo.

0 trabalho com os bebês requer delicadeza e um olhar aguçado para suas necessidades, para a efetivação de práticas humanizadoras, pois as ações sem reflexão podem, mesmo sem 
a intenção, transformar-se em ações desumanas com as crianças.

0 horário do jantar era realizado tal como o do almoço. As interações também eram precárias, e era comum nesse momento ouvir as professoras advertindo severamente as crianças: "Pode parar de brincar!"

Um excerto do registro do caderno de campo referente à turma do Berçário 2, da tarde, em 2010, ilustra a intervenção de uma professora nesse momento da rotina. A professora Tomásia fala bruscamente com Luiza: "Cadê sua colher? Já está grandinha para dar comida na sua boca, né? Você já sabe comer sozinha”. Essa cena chega a causar espanto, se lembrarmos que a professora estava falando com uma criança de aproximadamente dois anos.

Em situações similares a essa, percebe-se que as professoras deixavam de olhar as crianças como crianças pequenas, exigindo que elas se comportassem como adultos. Não se pode afirmar que essa atitude é adotada por todas as professoras no CEI. Entretanto, por meio das observações realizadas, é possível dizer que são comuns ações docentes que desconsideram as emoções das crianças e sua fase de desenvolvimento, e mais, que, apesar de haver professoras que não atuam dessa maneira, seu silêncio favorece que essas cenas sejam cada vez mais naturais e habituais no cotidiano do CEI. 0 silêncio das que não agem dessa maneira pode ser um indicador de que há um pacto entre elas para não interferir na autoridade da outra, num corporativismo que desrespeita a criança, levando em conta apenas os interesses dos adultos.

Ao ser questionado a respeito de algum momento da rotina que considerava não democrático com a criança, o professor Jovino assinalou justamente aquele das refeições. Apesar de incentivar a criança a se alimentar, esse momento não era prazeroso. 0 professor sublinhou dois fatores que o tornavam difícil: o primeiro era a localização inadequada do refeitório, que tinha suas laterais abertas e ficava em frente ao parque, local em que as crianças queriam ficar sempre. 0 segundo referia-se à impossibilidade de o professor alimentar-se junto com as crianças, por determinação da Secretaria Municipal de Educação. Acreditava que, ao realizar a refeição junto com as crianças, o professor poderia servir como um estímulo para elas provarem e conhecerem diferentes alimentos, que muitas vezes rejeitavam.

Com relação à questão de o adulto alimentar-se junto com a criança no CEI, é importante atentar para os riscos dessa proposição, se não se considerar a necessidade de mudança na estrutura, pois, da maneira como é organizado hoje, com muitas crianças almoçando ao mesmo tempo e em um curto período, com um número pequeno de adultos, torna-se de fato difícil possibilitar um momento de refeição tranquilo, tanto para a professora quanto para a criança.

Em síntese, nos momentos de alimentação, há pouca interação entre as professoras e as crianças, e muitas repreensões e não há nenhuma evidência que qualifıque as intervenções das docentes como alicerçadas em pressupostos pedagógicos. Essa situação revela que o trabalho com crianças pequenas, especialmente com os bebês, ainda é desprovido de uma intencionalidade pedagógica clara, o que reforça a permanência de práticas educativas improvisadas e sem reflexão, fruto de uma política pública que desconsidera a especificidade do trabalho com a primeira infância e não promove acompanhamento adequado do trabalho pedagógico e condições de trabalho necessárias para que as professoras possam atentar mais às necessidades das crianças.

\section{Momento do descanso}

0 momento do descanso ocorria depois do almoço, após a escovação dos dentes e as crianças não podiam optar por outra atividade. No berçário, todas eram colocadas nos berços. Aquelas que não ficavam deitadas para dormir, as professoras pegavam no colo e ninavam ou apenas balançavam o berço. 
Dormir era uma "atividade" obrigatória para as crianças. No caso das crianças maiores, todas deveriam deitar no colchonete e permanecer em silêncio. As luzes eram apagadas e as professoras ficavam com as crianças que não desejavam dormir até que dormissem. A descrição da observação realizada na sala do Minigrupo1 ilustra como se dava a interação entre as professoras e as crianças nesse momento, na maioria das salas:

As crianças chegam à sala e os colchonetes já estão com lençol e organizados; elas tiram os calçados e colocam embaixo dos colchonetes e em seguida pegam suas chupetas e seus travesseiros.

As professoras coordenam esse momento, observando e advertindo as crianças para que todas se deitem e permaneçam em silêncio. É comum as professoras fazerem observações que desqualificam a capacidade das crianças em realizar o que está sendo proposto.

Em determinado momento, a professora Ivanize dirige-se à professora Sidineia e diz: "A Poliana foi para o colchão de tênis, mas tem que ser, né? Se a Poliana fizer alguma coisa certinha... 0 que foi, Poliana? Não está conseguindo [tirar os sapatos]?". Ivanize é pouco cuidadosa ao falar com as crianças.

Poliana não responde, apenas olha para a professora e continua a tirar os tênis.

Parece que o silêncio e o olhar de Poliana expressam uma desaprovação a respeito da observação inadequada da professora. Mas, ao que tudo indica, a professora não percebe tal expressão e continua a atuar da mesma maneira com outras crianças.

Vejamos agora mais um trecho das notas de campo:

Na sequência, a professora Sidineia repreende uma criança, dizendo: "Por que
Emília está com o travesseiro da Isabella?" Emília devolve o travesseiro para Isabella e circula pela sala chorando, porque quer o travesseiro...

A professora Ivanize observa a cena e pergunta para a professora Sidineia: "0 que será que ela quer?” [referindo-se à Emília]. Não obtém resposta e logo se concentra em outra situação, ao constatar que Isabella não tem fraldas, dizendo a esta: "Mas hoje não tem fralda... Vou pegar de outra criança... Não adianta falar com a Isabella... Isabella, se você quiser fazer xixi, você fala?"

A criança responde afirmativamente com a cabeça.

Ao longo da observação desse momento na sala do Minigrupo 1, pode-se notar uma naturalidade nas reações das crianças diante das situações que ocorrem individualmente, evidenciando tratar-se de ocorrências corriqueiras, pois a maioria das crianças obedece às professoras, não conversa e deita tranquilamente nos colchões, sem se envolver com as outras crianças ou com as professoras. Apenas algumas poucas crianças transgridem as regras das professoras, brincando no colchão ou tentando conversar com o amigo, as quais são prontamente advertidas.

Vale atentar para a abordagem das professoras com as crianças. De maneira recorrente, elas falam com as crianças, mas dizem o nome da outra professora. Há um tom de ironia nessa forma de comunicação, que carece de reflexão e questionamentos:

Emília fala com a professora Ivanize, que não a compreende e pergunta: "Quer que eu deite com você? Vem buscar os tênis... Eu não tô te entendendo..." Emília chora...

Professora Ivanize continua: "Você não trouxe o seu [travesseiro] hoje? Você quer que eu faça um travesseiro para você? Eu faço um travesseiro para você..." 
Nesse momento, a professora Ivanize acolhedoramente improvisa um travesseiro e deita-se junto a Emília, acalmando-a.

Chega na sala Larissa, que retorna do banheiro descalça. Imediatamente, a professora Sidineia diz, ironicamente: "É para dormir de chinelo na mão, Ivanize?" (referindo-se a Larissa).

A professora Sidineia continua falando com Larissa e adverte: "Dá aqui o chinelo!" E acrescenta, ironicamente: "Logo quem... Essa menina aqui você sabe como ela é geniosa" (dirigindo-se à professora Ivanize).

A professora Ivanize continua com essa mesma forma de comunicação e, referindo-se a outra criança, diz: "Eu acho que eu vou brigar com o Silas, porque ele está tirando a cadeira do lugar..." (Silas está deitado, brincando com a cadeira).

Essa forma de diálogo causa consternação, especialmente porque as crianças ficam passivas diante dessa abordagem. 0 que nos leva a refletir: será que as professoras não percebiam que, naquele momento, as crianças estavam sendo expostas diante das outras crianças e dos adultos que estavam na sala? Parece que essas questões não eram alvo da preocupação das professoras; ao contrário, o objetivo daquele momento era um só: as crianças dormirem.

Analisemos mais um trecho do caderno de campo:

Entra na sala a professora Janete, que, ao ver Silas mexendo na cadeira, imediatamente diz para as outras professoras, mas olhando para a criança: "Vou levar ele pro berço!” Em tom de ameaça. E acrescenta ironicamente: "Essa sala é uma bênção!" Simultaneamente, a professora Sidineia adverte outras crianças: "Isabella, deixa a Poliana, que ela está descansando". E continua: "Tira a mão do tênis, Solange, agora chega!"
A professora Ivanize deita com outra criança.

Algumas crianças brincam com as mãos... Levantam... Olham as outras... Algumas já dormem... A sala fica bem tranquila.

A professora Ivanize, mesmo deitada com Gabriel, observa as outras crianças e adverte uma que acabou de bater a cabeça no chão: "Ei Hélio, sossega! Você bateu a cabeça? Fica quietinho que não bate!”

A professora Janete sai da sala e pouco depois retorna, aproxima-se das professoras e começa a conversar sobre cursos, concurso e outros assuntos. Às vezes, param de falar, quando uma delas se dirige a alguma criança que ainda não dormiu, e adverte: "Fecha esse olho aí!"

A professora Janete ameaça: "Amália, você quer ir para outra sala? Quer ir para o berço?"

Professora Ivanize: “Ah! Essa menina não tem noção... 0 berço para ela é prêmio..." Novamente, um conjunto de comentários preconceituosos com a criança e expressões de ameaça. A professora Sidineia levanta-se e dirige-se ao solário para comer alguma coisa, e a professora Janete vai ao seu encontro e ficam conversando.

A professora Ivanize muda Osmar de lugar, pois ele não parava quieto para dormir...

Encerro as minhas observações e, ao sair da sala, ainda há sete crianças acordadas, sem vontade de dormir.

É realmente espantosa a facilidade com que as professoras repreendem e ameaçam as crianças. Parece não haver uma preocupação em tentar compreender as manifestações infantis. Todas as ações concentram-se no controle e revelam uma compreensão de que situações de transgressões das crianças - nesse caso, não desejar dormir - devem ser resolvidas por meio de punições.

0 que considero grave nessa e em outras situações similares é a espontaneidade com 
que as professoras expressam afırmações depreciativas com relação às crianças, expondo-as de maneira desrespeitosa. Parece que forçar a criança a dormir, mesmo que ela não deseje, e utilizar ameaças é algo natural. Parece que não se dão conta da violência dessas práticas para a formação da personalidade da criança.

Ao entrevistar a professora Sidineia e perguntar sobre o momento do sono, ela reconheceu que era um momento em que não havia democracia com a criança. Disse que, de certa forma, falta com o respeito à criança, porque muitas delas aprenderam a dormir nesse horário no CEI, pois em casa dormiam quando desejavam. Entretanto, afirmou não ver outra maneira: todos precisavam dormir porque as crianças que não dormiam acordavam os que estavam dormindo, e ela considerava importante o descanso para a criança. Apesar de já ter vivenciado em outro CEI uma experiência diferente, em que uma professora passeava com as crianças que não dormiam, avaliou que essa medida atrapalhou o trabalho desenvolvido no período da tarde, pois as crianças dormiam mais tarde. Assim, considerava que, no horário do sono, "todos têm que dormir".

É intrigante que, ao perguntar se essas questões já haviam sido discutidas pelo grupo, a professora Sidineia respondeu afirmativamente e disse que, nas reuniões de formação, estudaram um texto que assinalava que muitas vezes os adultos utilizavam coação com as crianças, e ela considerava que isso ocorria na hora do sono. Ao ouvir seu relato, pareceu-me que havia uma conformação com o jeito como a rotina estava, como se afirmasse que "dos males é o menor”. Era uma contradição, pois a professora reconhecia que, da maneira que ocorria, o procedimento não era favorável à criança, mas parecia não conseguir ver alternativas de desafiar o cotidiano e desbravar novas formas de educação da criança, no contexto coletivo.

É preciso reconhecer que há fatores externos que extrapolam a posição de cada professora, como alerta Fernanda Carolina Dias Tristão (2004), ao analisar uma situação no momento de refeição:
[...] fica claro que não podemos ter a ingenuidade de achar que se as coisas não acontecem dentro da creche é por má vontade das professoras. Algumas vezes, as condições estruturais são realmente impeditivas. Entretanto, é bastante tênue a fronteira entre os reais impedimentos estruturais e a acomodação ou o temor de fazer diferente, ou, ainda, o deixar que a rotina atropele oportunidades de novas experiências. (TRISTÃO, 2004, p. 136).

A simbiose entre os componentes estruturais e as dificuldades das professoras em ousar novas formas de organização do tempo que privilegiem as experiências das crianças é enfatizada por algumas docentes e bem explicitada pela professora Karin, ao se referir à pressão das professoras da tarde, que desejavam chegar e encontrar as crianças dormindo para fazerem coisas externas ao trabalho, como almoçar, ler, conversar. Parece que existe um acordo tácito entre essas profissionais para garantir que as crianças durmam. Há uma pressão interna nas instituições de educação infantil que, de acordo com a professora Karin, não se referia apenas ao CEI analisado, pois, segundo seu relato, já aconteceu com ela em outra unidade em que trabalhou.

As observações desse momento no CEI muito se assemelham às questões apresentadas por Ana Maria Mello (1987), em artigo que relata e analisa a rotina das crianças em uma creche municipal na década de 1980, e às situações apresentadas na pesquisa de mestrado de Ângela Maria Scalabrin Coutinho (2002). Parece que - depois de mais de três décadas! - as interações entre crianças e professores permanecem iguais e nem mesmo a inserção, no quadro do CEI, de professoras em lugar das antigas pajens modificou sua qualidade. É intrigante como as diversas experiências realizadas para a flexibilização desse momento, na própria rede municipal, não são consideradas. 
Nesse momento da rotina, tal como nos horários de alimentação, não eram respeitados os direitos fundamentais das crianças deterseus ritmos biológicos considerados. Independentemente de terem sono ou não, as crianças deveriam dormir todas no mesmo horário.

\section{A especificidade do trabalho na educação infantil: integração entre cuidado e educação}

Nos três primeiros anos, a criança aprende a falar, a andar, a alimentar-se sozinha e estabelece comunicação com os adultos e crianças que estão ao seu redor. São práticas sociais efetivadas tanto no contexto educacional quanto familiar. Entretanto, é preciso lembrar que, na creche, tais práticas devem ser associadas ao conhecimento sobre o desenvolvimento da criança e à educação em espaços coletivos, não desvinculando o cuidado do corpo do desenvolvimento da personalidade da criança.

Além do respeito aos direitos das crianças para consolidar uma relação democrática, há outro elemento importante a considerar em seu processo de educação coletiva e que está diretamente ligado ao seu pleno desenvolvimento. Refiro-me à importância de os adultos aprenderem a escutar a criança pequena por meio de suas manifestações, nas quais as emoções, de acordo com Henri Wallon, ocupam lugar central.

Wallon (2007) afirma que a natureza das emoções é paradoxal, comportando tanto uma dimensão fisiológica quanto uma dimensão social. A expressão das emoções permite a passagem da dimensão orgânica para a dimensão psíquica, promovendo e sendo fruto da interação entre o sujeito e o grupo social. Os gestos e movimentos das crianças, assim, expressam o caráter fisiológico da emoção ou sensação, mas também, e ao mesmo tempo, atualizam/reasseguram seu caráter social - já que a dimensão social, além de se efetivar no contato com o outro por meio de sua emoção e afeto, é aprendida na interação.

A observação das relações estabelecidas entre professoras e crianças no cotidiano - especialmente nos momentos do descanso e da alimentação - mostrou como os adultos ainda têm dificuldade de escutar e compreender as manifestações das crianças, evidenciando a complexidade da educação das crianças pequenas, cuja linguagem oral está em desenvolvimento e necessita de um olhar acentuado para seus gestos e manifestações.

Ao longo das entrevistas, perguntei às professoras a respeito da inserção dos momentos de cuidado com o corpo, higiene, alimentação e descanso como temáticas do planejamento e das reuniões de formação. As respostas indicaram que essas ações não são alvo de reflexãojunto ao grupo de professoras, revelando não serem eles considerados como "pedagógicos", mas sim como ocasiões para a construção de hábitos e comportamentos que não requerem análise sistemática. A professora Doralice relatou que considerava importante a integração dessas temáticas na formação, mas que nunca havia pensado nisso; que, na verdade, as reuniões de formação semanais não davam conta desses debates e, ao planejar o trabalho com as crianças, muitas vezes esqueciam-se da integração entre cuidado e educação.

Esse relato, somado aos depoimentos da diretora Maria Vitória, reitera que há, ainda, dificuldade em entender o caráter educativo e formativo das ações de cuidado com o corpo junto às crianças, ou seja, que o cuidado com a criança é pedagógico! Apesar de fazer parte do contexto educativo e tomar grande parte do tempo da rotina, as ações de cuidado tornam-se "invisíveis", na medida em que estão presentes no cotidiano, mas não são consideradas contextos merecedores de reflexão.

De acordo com a diretora Maria Vitória, havia professoras que ainda não aceitavam que, em sua prática, tivessem de atuar com cuidados com o corpo, e que havia uma recusa velada, que se expressava nas ações junto às crianças. Segundo ela, algumas professoras acreditavam que essas ações deveriam ser desenvolvidas pelo auxiliar técnico de educação (ATE).

Ao analisar os motivos pelos quais os cuidados com o corpo são marginalizados em 
relação às “práticas pedagógicas”, Coutinho (2002) levanta duas hipóteses para compreender essa cisão. A primeira refere-se à herança assistencial, que acentua a proximidade entre trabalhos desenvolvidos com as crianças na instituição e o que é realizado no âmbito doméstico. A segunda trata da falta de conhecimentos sobre como fazer uma prática pedagógica diferente.

Além desses dois elementos identificados por Coutinho (2002), a análise das observações e dos depoimentos das professoras do CEI pesquisado evidencia o papel das emoções como mais um elemento que permeia a integração entre a educação e o cuidado e promove a marginalização das ações de cuidados com o corpo. Imbuídas de sentimentos de desvalorização por trabalharem com crianças pequenas, as professoras parecem negar inconscientemente o que é específico nesse segmento, nessa etapa da vida, em que as crianças dependem dos adultos para aprender a cuidar de si e relacionar-se com o outro. Os sentimentos de desvalorização e descontentamento afetam diretamente as relações com as crianças, promovendo uma simbiose de emoções que são fruto das questões de ordem estrutural, das políticas públicas e das questões de ordem pessoal (referentes à vida e à trajetória de cada professora), e provocam irritação em relação às crianças.

0 trabalho com as crianças pequenas exige dos adultos uma abertura emocional que não é considerada como temática pedagógica. Entretanto, as questões emocionais, apesar de não serem tratadas nos espaços de formação, atuam de forma invisível, funcionando como um "currículo oculto".

Augusta Foni (1998) afirma que, junto às necessidades de aprofundamento de temáticas específicas dos educadores, há também a necessidade de tratar de conteúdos que muitas vezes os professores precisam compartilhar, pois cotidianamente são solicitados a uma revisão de suas práticas, o que configura:

[...] uma atividade de trabalho que comporta uma fadiga física e psicológica, além de uma contínua colaboração com os colegas. Os sinais do cansaço são percebidos nos comentários fora de casa, na resistência à mudança, no fechamento em relação aos pais, no andamento alternado do empenho etc.[...]. (FONI, 1998, p. 157).

Foi recorrente, nas observações, ouvir as professoras relatarem que estavam muito cansadas e desanimadas em função dos problemas com a equipe de gestão, com as determinações da Secretaria de Educação, com as famílias, que transferiam suas responsabilidades para o CEI, e com as crianças, que apresentavam "comportamentos inadequados". 0 trabalho com a criança pequena em meio a esse cenário torna-se um desafio, que exige muito equilíbrio e clareza dos profissionais.

Apesar do reconhecimento da complexidade emocional que permeia a prática docente, por parte de muitas professoras, essa questão não é objeto de reflexão nos momentos de formação ou ao implantar a jornada da criança no CEI. E, como foi assinalado na descrição da rotina, as ações de cuidado com o corpo, alimentação e descanso são rituais pouco flexibilizados, independentes das necessidades das crianças, impedindo que se garanta o direito da criança a ter seus ritmos biológicos respeitados, com a compreensão de sua subjetividade.

De acordo com Heloísa Dantas (1992, p. 89), o caráter social das emoções é "anárquico e explosivo" e, portanto, não é previsível, o que assombra os educadores e justifica sua exclusão como temática pedagógica:

[...] na interação entre adultos e crianças, cuja temperatura emocional é mais elevada [...] tão raramente tematizada, esta questão passa assim para o primeiro plano: a educação da emoção deve ser incluída entre os propósitos da ação pedagógica, o que supõe conhecimento íntimo do seu modo de funcionamento. (DANTAS, 1992, p. 89). 
Além da necessidade das crianças, é preciso atentar para a importância de compreender as professoras, suas emoções e concepções sobre o trabalho com a criança pequena, para, assim, conseguir desenvolver um trabalho de formação que realmente contribua para seu desenvolvimento e para mudanças das práticas pedagógicas. Nesse sentido, buscou-se captar alguns elementos que pudessem subsidiar a análise das relações entre adultos e crianças e, ao entrevistar as professoras, perguntei qual o motivo da escolha do CEI como segmento de atuação. Foi frequente nas entrevistas o argumento de que não escolheram trabalhar na educação infantil. Muitas encontraram nessa modalidade o meio de inserir-se na carreira pública do magistério do município de São Paulo. Outras prestaram o concurso e não sabiam como era o trabalho no CEI; duas professoras relataram o choque ao saber que teriam de trocar bebês. Uma delas contou que, ao se deparar com a tarefa de trocar fraldas, vomitou no primeiro dia e faltou três dias consecutivos.

0 relato da professora Karin, do Berçário 1, pode ilustrar como muitos educadores chegaram ao CEI por acaso:

[...] quando eu prestei concurso pra cá, eu não sabia que era creche, eu achava que era para Emei. [...] Eu não li o edital e prestei o concurso. E não tinha dinheiro na época, e eu não ia prestar [...] Uma amiga minha falou "não, eu pago pra você". Aí pagou pra mim e comprou duas apostilas, a gente nem leu as apostilas, ficava mais conversando do que lendo, na verdade. E nós passamos e eu entrei. Então, estou já há sete anos no CEI e Emef. (Karin, professora).

Karin afırma que não escolheu trabalhar com crianças pequenas e declara: "E, assim, falar sinceramente para você, eu não gosto de criança muito pequena, acho eles muito dependentes [...] eu acho melhor, acho que você desenvolve melhor com crianças maiores, eu gosto muito mais [...]”. Ao final dessa afırmação, a professora disse que tinha intenção de se exonerar do cargo e ficar apenas no ensino fundamental, mas que, em função de questões financeiras, permaneceria até seus filhos concluírem o ensino superior.

0 fator surpresa - nesse caso, choque dos educadores com relação ao trabalho com as crianças pequenas é um dos elementos que dificultam o reconhecimento da especificidade da educação infantil. Por se associar inconscientemente esse trabalho com algo que não necessita de formação, como ocorria nas primeiras creches, há uma decepção com o trabalho, que pode levar a uma intolerância com a criança, especialmente na disponibilidade de interagir com ela. Janusz Korczak alerta sobre esse perigo:

Que desencanto para um educador que no começo de sua carreira pensava que iria entrar num mundo de almas puras, ternas e francas. Não lhe disseram que bastaria mostrar boa vontade para atrair rapidamente a simpatia deles e obter a sua confiança? Infeliz, decepcionado, revolta-se contra as crianças, em vez de ficar com raiva daqueles que na realidade o enganaram... E também de si próprio, por ter acreditado neles. Não é culpa das crianças se lhes disseram que esse trabalho seria agradável e fácil. (KORCZAK, 1997, p. 236).

A educação infantil é um segmento novo no sistema educacional e, ao atentarmos para sua trajetória histórica, podemos perceber que o trabalho com crianças pequenas atrelou-se ao papel da mãe, buscando muitas vezes substituí-la. A identidade das instituições de educação infantil era fortemente vinculada ao modelo de funcionamento doméstico da família. A inserção das creches no sistema educacional e a busca para romper com a herança assistencialista, reconhecendo a creche como um contexto educativo em que a atuação das professoras requer conhecimentos científicos e planejamento de sua prática, está em construção, o que promove 
ainda muitas incertezas e dúvidas quanto a seu caráter educacional.

\section{Considerações finais}

Compreender a complexidade do trabalho com a criança pequena é um desafio e requer disposição para atuar numa área que exige análise crítica com relação à efetividade das instituições, no sentido de se colocar as crianças como foco do trabalho. A coragem de reconhecer as contradições das práticas cotidianas, compreendendo-as como o resultado de um trabalho não individual, mas coletivo - de todos que atuam nas unidades de educação infantil -, longe de reforçar a impotência e provocar o desânimo, tem o potencial de construir experiências em que as professoras assumam a autoria da prática pedagógica e, junto com os demais profissionais da instituição, busquem formas de atuação que realmente promovam novas perspectivas de educação da criança pequena em espaços públicos, contribuindo para a constituição de políticas públicas que realmente respeitem os direitos das crianças.

A observação dos momentos da rotina no CEI pesquisado leva-nos a afirmar que tal rotina ainda é um desafio à efetivação de ações que promovam o respeito à individualidade e singularidade das crianças. A ausência de um debate rigoroso e permanente sobre o cotidiano favorece uma ritualização das ações, obstruindo possibilidades de mudança na organização do trabalho e na qualidade das interações.

A ideia de que a criança pequena tem de ser controlada aparece nas ações do cotidiano e requer um olhar sensível e crítico, para reconhecer que a concepção de criança expressa nessas ações diferencia-se frontalmente da apresentada no projeto pedagógico e nas entrevistas das professoras.

Constatou-se que as emoções expressas pelas crianças nos momentos das refeições e descanso são, em grande medida, desconsideradas. Além disso, as entrevistas das professoras e da equipe de gestão, articuladas às observações do cotidiano, revelaram contradições entre a forma como compreendem a importância da integração entre cuidado e educação e as práticas efetivadas. A cisão entre as ações de cuidado e educação está presente no cotidiano do CEI pesquisado, e as ações de cuidado com o corpo, promovidas pelas professoras junto às crianças, são vulneráveis às emoções dos adultos.

A integração de cuidado e educação, considerando o papel das emoções nesse processo, deve ser levada em conta para a constituição das propostas pedagógicas em cada creche, de forma a garantir a efetivação de novas práticas de socialização, como é apontado nas Diretrizes Curriculares Nacionais para a Educação Infantil (BRASIL, 2009). A defınição das políticas públicas para a rede de educação infantil não pode desconsiderar esses aspectos que compõem o cotidiano das relações entre crianças e adultos, pois, para torná-las democráticas, é preciso investir na formação dos professores e na melhoria das condições objetivas de trabalho. A qualificação das relações entre adultos e crianças nas unidades de educação infantil deve, portanto, ser uma diretriz da política pública.

A concepção de criança e infância é nosso ponto de partida e também nosso ponto de chegada. Compreender a criança em sua singularidade, sem desconsiderar o contexto em que está inserida e a maneira como a sociedade acolhe e reconhece a infância, é um elemento importante para evitar promover análises isoladas do contexto social. Nessa perspectiva, trata-se de aprofundar a discussão sobre a especificidade da educação infantil, sem medo de lidar com as temáticas do afeto, do cuidado, dos sentimentos, das emoções, e de reconhecer que as instituições de educação infantil têm o cuidado e a educação como a dimensão política da existência humana. 


\section{Referências}

BARBOSA, Maria Carmen Silveira. Por amor e por força: rotinas na educação infantil. Porto Alegre: Artmed, 2006.

BATISTA, Rosa. A rotina no dia a dia da creche: entre o proposto e o vivido. Dissertação (Mestrado em Educação) - Centro de Ciências da Educação, Universidade Federal de Santa Catarina, Florianópolis, 1998.

BRASIL. Conselho Nacional de Educação. Câmara de Educação Básica. Resolução nº 5, de 17 de dezembro de 2009. Fixa as diretrizes curriculares nacionais para a educação infantil. Brasília, DF: CNE, 2009. Disponível em: <http://portal.mec.gov.br/index. php?option=com_content\&view=article\&id=13684\%3Aresolucoes-ceb>. Acesso em: 6 maio 2013.

COUTINHO, Ângela Maria Scalabrin. As crianças no interior da creche: a educação e o cuidado nos momentos de sono, higiene e alimentação. Dissertação (Mestrado em Educação) - Centro de Ciências de Educação, Universidade Federal de Santa Catarina, Florianópolis, 2002.

DANTAS, Heloísa. A afetividade e a construção do sujeito na psicogenética de Wallon. In: LA TAILLE, Yves; OLIVEIRA, Marta Kohl; DANTAS, Heloísa. Piaget, Vygotsky, Wallon: teorias psicogenéticas em discussão. São Paulo: Summus, 1992. p. 85-100.

GUIMARÃES, Daniela. Relações entre adultos e bebês na creche: 0 cuidado como ética. São Paulo: Cortez, 2011.

FONI, Augusta. A programação. In: BONDIOLI, Anna; MANTOVANI, Susana (Org.). Manual de educação infantil. 9. ed. Porto Alegre: Artmed, 1998. p. 140-160.

KORCZAK, Janusz. Como amar uma criança. 4. ed. Rio de Janeiro: Paz e Terra, 1997.

MELLO, Ana Maria. Tempo de mudança na creche Vila Praia. Cadernos de Pesquisa, São Paulo, n. 60, p. 79-84, fev. 1987.

TRISTÃO, Fernanda Carolina Dias. Ser professora de bebês: um estudo de caso em uma creche conveniada. Dissertação (Mestrado em Educação) - Centro de Ciências da Educação, Universidade Federal de Santa Catarina, Florianópolis, 2004.

WALLON, Henri. A evolução psicológica da criança. São Paulo: Martins Fontes, 2007.

Recebido em: 12.03.2015

Aprovado em: 27.11.2015

Maria Aparecida Guedes Monção é doutora em Educação pela Faculdade de Educação da Universidade de São Paulo. Professora do Programa de Pós-Graduação em Educação da Universidade Cidade de São Paulo (Unicid). É membro da coordenação do Fórum Municipal de Educação Infantil de São Paulo desde 2012. 